\title{
Improving shared decision-making in patients with hearing impairment in difficult listening situations
}

Timothy Shun Man Chu ${ }^{1}$, Michael Mather ${ }^{2}$, Nicholas Dawe ${ }^{3}$, Professor Janet Wilson ${ }^{4}$

\section{Background}

Blustein et al. ${ }^{1}$ highlighted the challenges hearingimpaired patients face in difficult listening situations. These situations include many healthcare settings, especially acute care settings.

Receptive communication deficiency limits capacity for shared decision making, particularly in vulnerable patients. This poses a substantial risk to patient care. Hearing loss is also independently associated with accelerated cognitive decline ${ }^{2}$.

\section{Objectives}

- To establish the availability of Personal Assistive Listening Devices (PALDs) in audiology departments across the United Kingdom.

- To identify current practices of different NHS Trusts.

\section{Methods}

Telephone survey of 14 English and Scottish Audiology departments.

\section{Results}

11 out of the 14 trusts included have PALDs available (Figure 1). The varied types of PALDs and practices of the centres were documented (Table 1).

Some units, including prominent centres for otology, offer hearing aids to such patients, but typically these aids are received well after discharge and fail to help patients as they navigate the communication complexities of their acute admission ${ }^{3}$.

The study also detected several barriers to consistent supply, including the initial cost of devices, reports of their frequent disappearance after being loaned, and concerns about infection control.

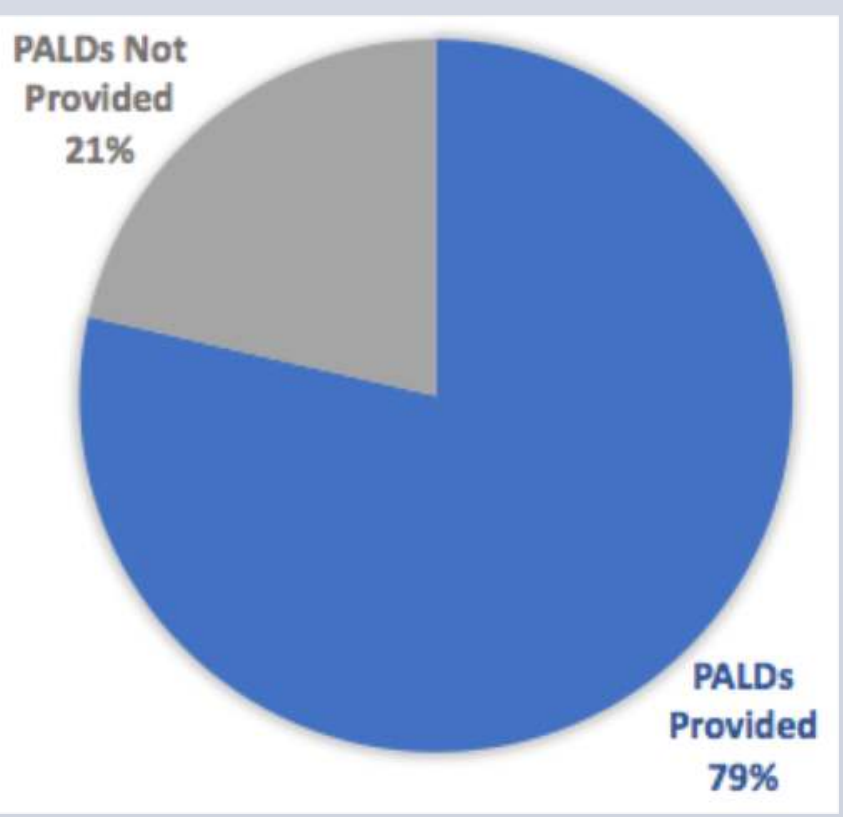

Figure 1 Proportion of centres with PALDs provided in difficult listening settings.

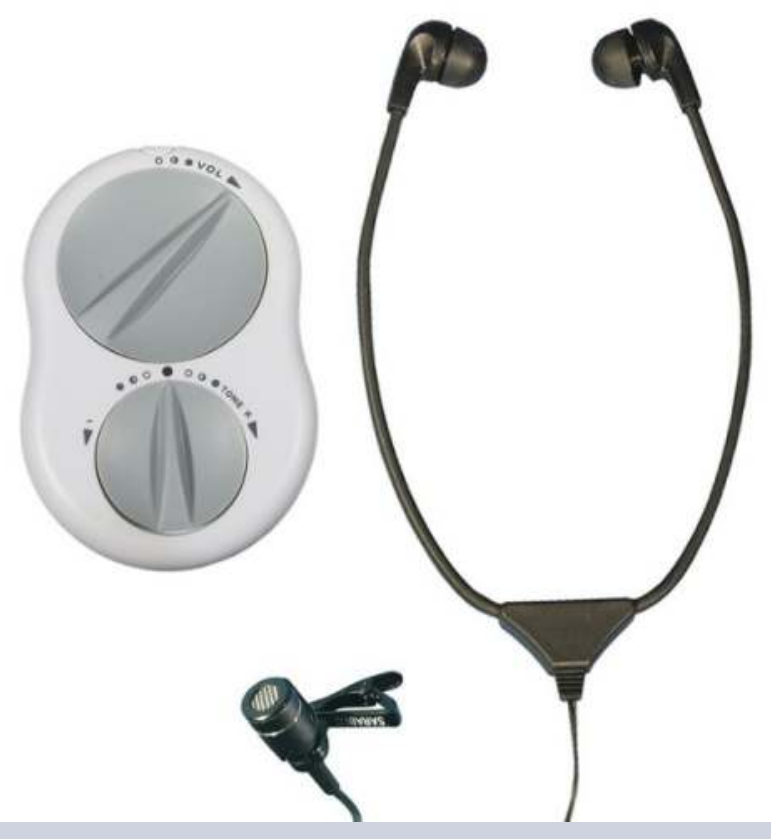

Picture 1 Example of a PALD (Sarabecs)
Table 1 Survey results of 14 trusts reporting availabilities, types of PALDs and current practices.

\begin{tabular}{|c|c|}
\hline Hospital NHS Trust & Devices and Current Practice \\
\hline \multicolumn{2}{|c|}{ England } \\
\hline South Tees Hospitals NHS Foundation Trust & Sarabecs (currently lost) \\
\hline North Cumbria University Hospitals NHS Trust & Hearing aids arranged prior to discharge \\
\hline City Hospitals Sunderland NHS Foundation Trust & Hearing aids arranged prior to discharge \\
\hline $\begin{array}{l}\text { County Durham and Darlington NHS Foundation } \\
\text { Trust }\end{array}$ & Sarabecs \\
\hline $\begin{array}{l}\text { Cambridge University Hospitals NHS Foundation } \\
\text { Trust }\end{array}$ & None \\
\hline Plymouth Hospitals NHS Trust & Minitech communicators on every ward \\
\hline Nottingham University Hospital NHS Trust & $\begin{array}{l}\text { Echotech personal listeners and personal loop } \\
\text { systems }\end{array}$ \\
\hline $\begin{array}{l}\text { University College London Hospitals NHS } \\
\text { Foundation Trust }\end{array}$ & Pocket talkers \\
\hline $\begin{array}{l}\text { Blackpool Teaching Hospitals NHS Foundation } \\
\text { Trust }\end{array}$ & $\begin{array}{l}\text { Bone conduction hearing aids and } \\
\text { communicators }\end{array}$ \\
\hline \multicolumn{2}{|c|}{ Scotland } \\
\hline NHS Greater Glasgow and Clyde - New Victoria & Puretone or bone conduction hearing aids \\
\hline $\begin{array}{l}\text { NHS Greater Glasgow and Clyde - Gartnavel } \\
\text { General }\end{array}$ & Sarabec \\
\hline NHS Tayside & Connevans communicators \\
\hline NHS Grampian & Powerdome \\
\hline NHS Forth Valley & Connevans \\
\hline
\end{tabular}

\section{Discussion/ Conclusion}

The availability of communicators to patients during their admission to acute medical wards is inconsistent, and to some extent, dependent upon colocation of audiology departments with emergency medical assessment units and on the acute medical team being aware of such facilities. Where audiology is off-site, communicators will only become available where receiving medical units have made independent provision.

We identified isolated examples of highly proactive supply, such as Plymouth Hospitals NHS Trust, where assisted hearing devices are available on every ward. A minority of other audiology departments promote "deaf awareness training."

We encourage all doctors whose patients have hearing impairments, or potential hearing impairments masked by cognitive decline, to develop the provision of devices in their department in conjunction with their local audiology lead.

\section{References}

1. Blustein J, Weinstein B, Chodosh J. Tackling hearing loss to improve the care of older adults. BMJ. 2018 Jan;360:k21. 2. Lin FR, Yaffe K, Xia J, et al., Health ABC Study Group. Hearing loss and cognitive decline in older adults. JAMA Intern Med 2013;173:293-9.

3. Mather MW, Dawe N, Wilson J. Inconsistent availability of hearing aids during acute admission. BMJ. 2018 May;361;k1944.

Picture 1: Hearing Direct. Sarabecs Crescendo 60/1 Personal Amplifier. 2017. 